\title{
Analysis of the Influence Factors of Differential Settlement of High Embankment in Mountain Area
}

\author{
Min Geng, Yuanming Dou \\ College of Civil Engineering, Hebei University of Technology, Tianjin, China \\ Email: gengmin45@163.com, douyuanming@163.com
}

Received August 15, 2012; revised September 18, 2012; accepted September 30, 2012

\begin{abstract}
This paper reveals and analyses various influence factors which cause differential settlement of high embankment in mountain area using indoor consolidation test and field loading test. In this research, the actual stress characteristics of high embankment are simplified, stability compression value of stuffing with loads under lateral restricted conditions can be measured, e-p curves and p-s curves are drawn, we can calculate compression modulus as computation criteria to estimate the settlement of high embankment. The results indicate that unconsolidated flow of high embankment is the main factor to cause differential settlement of high embankment in mountain area. As the soil consolidated, compressive deformation and the strength gradually increase, the bearing capacity of the foundation is enhanced to reduce differential settlement of the post-construction of high embankment.
\end{abstract}

Keywords: Road Engineering; High Embankment; Differential Settlement; Consolidation Test

\section{Introduction}

With the rapid development of economy in China, the construction of freeway also occurs in mountain area. Mountain has complicated topography and geological condition, and contains many high embankments, deep cuttings and subgrade of cut-and-fill. High embankment is the most common among these subgrade forms. The characteristics of high embankment are as follows: big stuffing height, stuffing in large quantities, heavy stuffing weight, taking up wide areas. Overall instability and differential settlement of subgrade are the main modes which cause high embankment destroy. Differential settlement is an especially common problem which makes construction personnel confused for years.

Excessive settlement caused by serious foundation settlement may affect freeway normal operation, this is because the height of high embankment is relatively high, compression settlement which is produced by stuffing gravity stress is larger, and it is beyond the allowable scope of the pavement structure layer and leads to settlement and craze of the pavement [1]. It is essential to take into account the construction of high embankment for reducing differential settlement and improving the quality of the mountain freeway.

This paper studies various influence factors of differential settlement of high embankment in mountain area based on a large amount of investigation. The results of the study provide relevant theoretical basis to prevent differential settlement and serve the construction of the freeway better.

\section{Analysis of the Influence Factors of Differential Settlement}

Deformation of high embankment will be produced under gravity and vehicle load. Differential settlement commonly occurs in the following areas: geology, topography, groundwater, surface water and cut-and-fill and stuffing which are greatly changed. Settlement or consolidation deformation which are caused by weak foundation, loosen or damp stuffing may lead to excessive deformation of pavement and the enlargement of stress, which may affect the normal use of freeway. The results indicate that the natural factors and the human factors [2] are the main factors to cause the settlement of subgrade.

\subsection{Natural Factors}

Natural factors include: 1) Topography: the steep terrain, if drainage facilities undeserved or geologic conditions poor, it is easy to decrease the strength and stability of embankment; 2) Climate: seasonal climate makes moisture of the soil in the state of liquid or gas move from hot to cold and amass, which leads to the destruction of embankment; 3) Hydrogeology: these places are possible to cause differential settlement of subgrade such as groundwater level, groundwater movement, spring, interlayer water and so on; 4) Stuffing: different stuffing have an 
important role on the stability of high embankment. Generally speaking, soil-stone stuffing is superior to sandy soil, sandy soil is better than sand; 5) Geology: rock types and weathering degree, strata towards, and bedding, have certain influence toward the embankment; 6) Plant covering: plant covering layer plays consolidate role in topsoil to some degree, also can enhance the stability of embankment.

\subsection{Human Factors}

Human factors include: 1) Load effect: static load and dynamic load act on embankment, stress generated in internal embankment by static load increases with depth, dynamic load decreases with depth. With the increasing of the flow of traffic, the actions of heavy vehicles in a long period will produce differential settlement of embankment; 2) The construction methods: only choosing good stuffing, correcting stuffing method, suitable construction machinery, scientific and reasonable construction can guarantee the stability of embankment; 3) Maintenance measure: Taking maintenance measures in construction and post-construction can ensure embankment with high strength and the stability in service deadline.

\subsection{Mechanism Analysis}

Compression deformation of the soil leads to subgrade settlement along the gravity direction. That stuffing has different compressibility or the upper structure load is different can cause differential settlement of embankment [3].

Under different loads, pore water leaks slowly, volume is gradually compressed, effective stress of the soil increases, excess pore water pressure gradually dissipate until disappear completely. This process is said to be consolidation.

Soil consolidation has two characteristics: volume reduction; related to time. Effective stress principle is: when load acts on soil, pore water takes on the load, then, with pore water gradually exudes, pore water pressure evaporates and effective stress gradually increases. Total stress $\sigma$, effective stress $\sigma^{\prime}$ and excess pore water pressure $\mu$ have relationship like this:

$$
\sigma=\sigma^{\prime}+\mu
$$

Terzaghi one-dimensional consolidation differential equation is:

$$
\frac{\partial u}{\partial t}=C_{v} \frac{\partial^{2} u}{\partial^{2} t}
$$

where, $C_{v}$ represents soil consolidation coefficient.

$$
C_{v}=\frac{k}{m_{v} \gamma_{w}}=\frac{K\left(1+e_{0}\right)}{\gamma_{w} \alpha_{v}}
$$

where, $k$ is hydraulic conductivity of soil; $m_{v}$ is volume compression coefficient; $\gamma_{w}$ is water specific weight; $\alpha_{v}$ is vertical compression coefficient; $e_{0}$ is soil initial void ration.

Under the action of effective stress, deformation produced using soil skeleton include: instantaneous deformation and consolidation deformation. When effective stress is discharged, recoverable deformation is called elastic deformation; unrecoverable deformation is called plastic deformation. Elastic deformation and plastic deformation are collectively called secondary consolidation deformation [4]. Therefore, the final settlement of foundation is divided into three parts by its deformation characters: instantaneous settlement, consolidation settlement and secondary consolidation settlement, their relations are shown as follows:

$$
S=S_{d}+S_{c}+S_{s}
$$

where, $S$ is foundation final settlement; $S_{d}$ is foundation instantaneous settlement; $S_{c}$ is foundation consolidation settlement; $S_{S}$ is foundation secondary consolidation settlement.

\section{Indoor Consolidation Test and Field Loading Test}

\subsection{Indoor Consolidation Test}

This study investigated stuffing of high embankment of some mountain freeway from Xingtai and carried out indoor consolidation test by consolidation apparatus.

Test materials are mainly powder clay soil and powder soil from undisturbed soil of freeway site. Consolidation test uses ring knife of which inside diameter is 8 centimeters, sectional area is 50 square centimeters, and height is 2 centimeters. There are four groups soil samples from undisturbed samples, the physical indices of soil sample are summarized in Table 1.

Through consolidation compression test toward four soil samples, the pressure are $50 \mathrm{kPa}, 100 \mathrm{kPa}, 200 \mathrm{kPa}$,

Table 1. Physical indices of soil samples.

\begin{tabular}{ccccc}
\hline Soil sample numbers & (1) & (2) & (3) & (4) \\
\hline Water content $\omega / \%$ & 25.30 & 25.06 & 24.30 & 23.85 \\
Dry density $\rho_{d} /\left(\mathrm{g} \cdot \mathrm{cm}^{3}\right)$ & 1.65 & 1.63 & 1.60 & 1.61 \\
Specific gravity $G_{s}$ & 2.73 & 2.75 & 2.74 & 2.76 \\
$\quad$ Void ratio $e_{0}$ & 0.68 & 0.67 & 0.65 & 0.61 \\
Liquid limit $\omega_{L} / \%$ & 32.0 & 30.8 & 28.6 & 27.9 \\
Plastic limit $\omega_{P} / \%$ & 21.4 & 20.5 & 18.7 & 18.2 \\
Plastic index $I_{P}$ & 10.6 & 10.3 & 9.9 & 9.7 \\
Liquid index $I_{L}$ & 0.37 & 0.44 & 0.57 & 0.58 \\
\hline
\end{tabular}


and $400 \mathrm{kPa}$, test data and calculation results are respectively shown in Tables 2 and $\mathbf{3}$.

Table 2. Test data.

\begin{tabular}{|c|c|c|c|c|}
\hline Sample & (1) & (2) & (3) & (4) \\
\hline Load (kPa) & \multicolumn{4}{|c|}{ Void Ratio/e } \\
\hline 50 & 0.455 & 0.456 & 0.458 & 0.458 \\
\hline 100 & 0.443 & 0.446 & 0.447 & 0.445 \\
\hline 200 & 0.432 & 0.431 & 0.431 & 0.428 \\
\hline 400 & 0.424 & 0.422 & 0.426 & 0.428 \\
\hline
\end{tabular}

Table 3. Consolidation test results.

\begin{tabular}{ccc}
\hline Soil number & $\begin{array}{c}\text { Compression } \\
\text { coefficient } / \boldsymbol{\alpha}\end{array}$ & $\begin{array}{c}\text { Compression } \\
\text { modulus/ } \boldsymbol{E}_{\boldsymbol{s}}\end{array}$ \\
\hline (1) & 0.15 & 9.6 \\
(2) & 0.12 & 12.0 \\
(3) & 0.11 & 13.2 \\
(4) & 0.09 & 16.1 \\
\hline
\end{tabular}
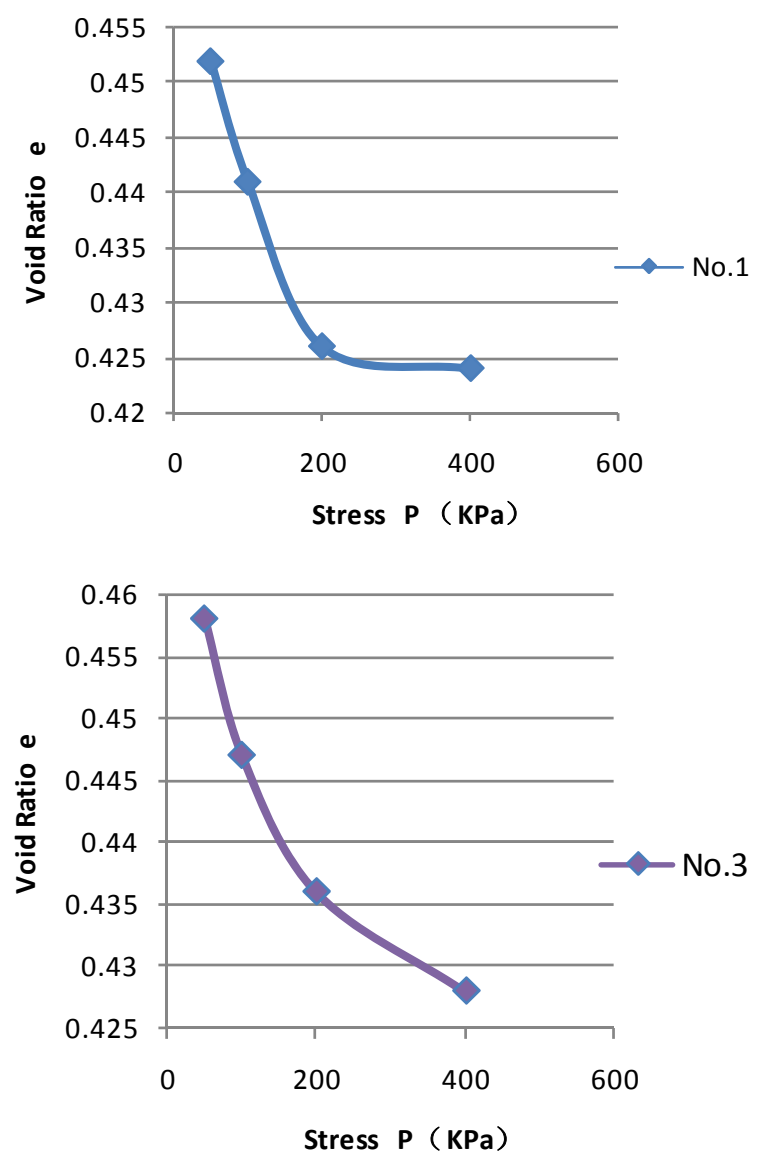

Indoor consolidation test results are shown in Figure 1.

\subsection{Field Loading Test}

Field loading test pressures load to the load plate which is placed on foundation soil through the jacks in engineering field, use dial indicators to record settlement changes over time and stable settlement [5]. Test data are shown in Table 4, field loading test results are shown in Figure 2.

\subsection{Test Results}

Analysis of the results shows that different compressibility soils have different curve, steep curve indicates that under the action of stress increment, soil pore ratio is decrease sharply, soil compressibility is higher. Compression modulus $E_{s}$ changes with pressure, compression modulus $E_{s}$ and compression coefficient $\alpha$ of stuffing are inversely proportional, the larger compression modulus $E_{s}$, the smaller compression coefficient $\alpha$ and the lower soil compressibility. Accordingly, soil settlement amount is smaller.
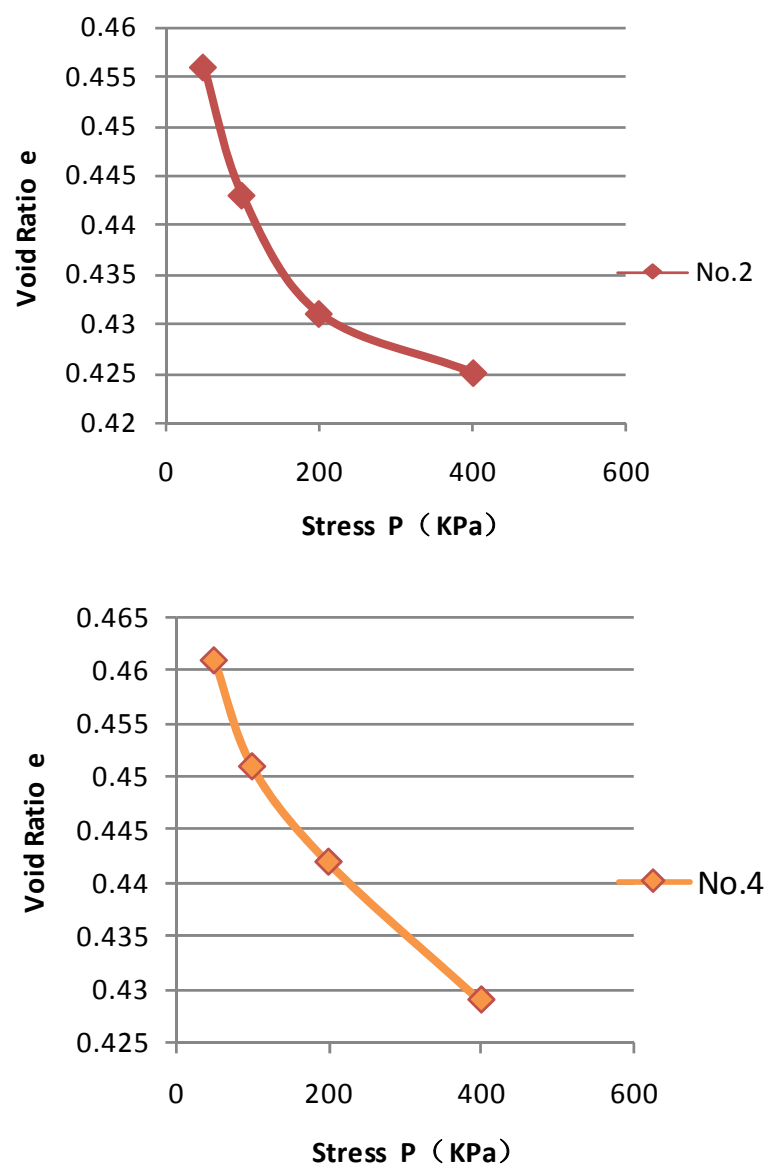

Figure 1. e-p curves of four groups undisturbed soil. 
Table 4. Field loading test data.

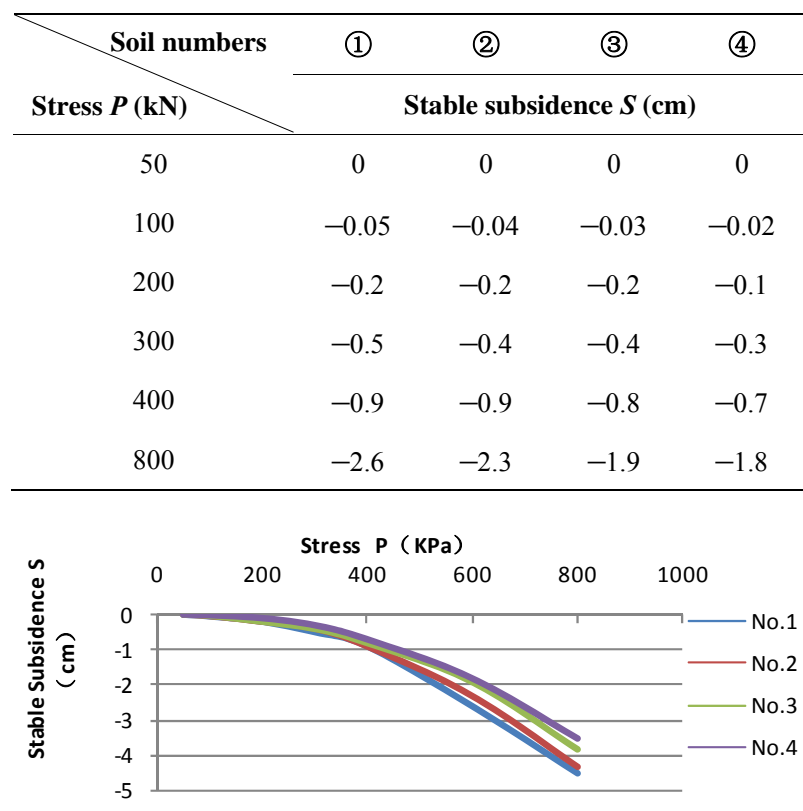

Figure 2. p-s curves of four groups undisturbed soil.

\section{Conclusions}

This study is simplified from the actual stress characteristics of mountain high embankment, the results indicated the following conclusions and suggestions:

Differential settlement of high embankment is derived mainly from compress deformation of stuffing, enhancing compression modulus of stuffing can effectively control differential settlement of high embankment.
Improving stuffing permeability and providing good drainage condition of subgrade, accelerating stuffing period consolidation deformation, extending embankment construction, these can make consolidation gain time to compress.

The main reason which causes differential settlement of high embankment is unconsolidation flow of high embankment. As the soil consolidated, compressive deformation and strength of the soil gradually increase, thus the bearing capacity of the foundation also enhances and is reduced differential settlement of post-construction of mountain high embankment.

\section{REFERENCES}

[1] J. M. Zi, H. X. Zhou, H. Li, et al., "Finite Element Analysis of Subside on High Embankment," Journal of Huazhong University of Science and Technology, Vol. 21, No. 4, 2004.

[2] CCCC Second Highway Consultants Co. Ltd., "Subgrade," China Communications Press, Beijing, 1996.

[3] J. Y. Shi, Y. X. Wen, G. H. Lei, et al., "Discussion on Consolidation Test and Some Relative Problems," Journal of Hohai University (Natural Sciences), Vol. 32, No. 2, 2004, pp. 213-215.

[4] X. Y. Xu, "The Research on Subside Character and Prediction Method for High Embankment," Changsha University of Science and Technology, Hunan, 2005.

[5] P. C. Zheng, Y. Lou and G. X. Meng, "Study of Field Loading Test for Composite Foundation," Dam Observation and Geotechnical Tests, Vol. 21, No. 1, 1997. 